\title{
Temporomandibular Joint Monoarthritis in Rheumatoid Arthritis - A Rare Case Report
}

\author{
*Shahin MA ${ }^{1}$, Karmacharya $S^{2}$, Islam $A^{3}$, Khan $M^{4}$, Morshed $A^{4}$, Razon $S^{6}$, Choudhury MR ${ }^{7}$
}

\begin{abstract}
Rheumatoid arthritis (RA) is a chronic, systemic, autoimmune inflammatory disorder that is characterized by joint inflammation, erosive properties and symmetric multiple joint involvement. Temporomandibular joint (TMJ) is very rare to be affected in the early phase of the disease, thus posing diagnostic challenges for the rheumatologist. TMJ complaints are present in about more than $50 \%$ of patients of RA.TMJ is usually among the last joint to be involved and is associated with many clinical signs and symptoms of which pain is a major problem leading to inflammation, limited movements, swelling, joint stiffness, and muscle spasm. Here reported case is 64 years old male, ex-smoker, diagnosed case of diabetes mellitus for 7 years, hypertension for 2 years, came to hospital with the complains of pain in left jaw for 1 year. He had no history of other joint pain, morning stiffness or any deformities. The patient was diagnosed as a case of rheumatoid arthritis on the basis of inflammatory monoarthritis with high titer positive RA factor and anti CCP. The patient gradually improved after treatment with methotrexate. Inflammatory markers like ESR dropped down with the clinical improvement. TMJ is seldom joint to be affected first in the disease course.
\end{abstract}

Keywords: Rheumatoid arthritis, temporomandibular joint arthritis

1. ${ }^{*}$ Dr. Md. Abu Shahin, Associate Professor, Department of Rheumatology, BSMMU

2. Dr. Sudhir Karmacharya, Resident Phase B, Department of Rheumatology, BSMMU

3. Dr. Md. Ariful Islam, Assistant Professor, Department of Rheumatology, BSMMU

4. Dr. Mamun Khan, Resident Phase B, Department of Rheumatology, BSMMU

5. Dr. Abdulla-Al-Morshed, Resident Phase B, Department of Rheumatology, BSMMU

6. Dr. Soleman Razon, Resident Phase B, Department of Rheumatology, BSMMU

7. Dr. Minhaj Rahim Choudhury, Professor, Department of Rheumatology, BSMMU

*For correspondence

\section{INTRODUCTION}

Rheumatoid arthritis (RA) is a systemic autoimmune condition with variable manifestations, characterized by symmetric polyarticular inflammation, predominantly in small joints of upper limbs which can lead to progressive joint damage. It is associated with substantial functional disability, morbidity, and accelerated mortality. The prevalence of RA is estimated at $1 \%$ in most developed countries, with a frequency ranging from less than or equal to $0.1 \%$ to $1.9 \%$ in surveys from different parts of the world. More than $50 \%$ of patients with rheumatoid arthritis have involvement of the TMJ. The approximate female-male ratio is 3:1. This TMJ is very rare to be affected in the early phase of the disease and isolated TMJ involvement is rarer. Here we are presenting a patient who had isolated TMJ involvement and finally diagnosed as RA.

\section{CASE SUMMARY}

A 64 years old male, ex-smoker, diagnosed case of diabetes mellitus for 7 years, hypertension for 2 years, came to our hospital with the complaints of pain in left jaw for 1 year. Initially pain was mild; it was progressively increasing, more marked in the morning making him difficulty in opening mouth. For last 2 months pain was throbbing in nature, severe and radiating to upper and lower jaw. He was unable to chew solid food and he even used to feel pain during speaking. The patient also complained burning and tingling sensation over same area which was aggravated on exposure to cold water for last 5 months. There was no history of low back pain or pain in other joints. No history of headache, blurring of vision and dental pain. His blood sugar was well controlled with tablet metformin $500 \mathrm{mg}$ daily and tablet Linagliptin $5 \mathrm{mg}$ daily. There was no history of hypoglycemic attack. He was a known case of hypertension for 2 years for which he was taking Bisoprolol $2.5 \mathrm{mg}$ daily and his blood pressure was within normal limit. He developed myocardial infarction in March 2019 and primary PCI was done. There was no family history of skin lesion suggestive of psoriasis. No drug history like steroid and bisphosphonate. 
On examination patient was ill looking and anxious. Pulse was 72 beats per minute; blood pressure was $130 / 70 \mathrm{~mm}$ of $\mathrm{Hg}$, no postural hypotension, and respiratory rate was 17 breaths per minute, temperature was 98 . There was no palpable lymph node. Thyroid gland was normal. There was grade tenderness over the left TM joint. Examination of all other system reveals no abnormalities.

Investigation reports reveal: $\mathrm{Hb}$ was $11.3 \mathrm{gm} / \mathrm{dl}$, total leucocyte count was $6.8 \mathrm{X} 10^{9} / \mu \mathrm{L}$, platelet was $200 \mathrm{X}$ $10^{3} / \mu \mathrm{L}$ and $\mathrm{RBC}$ count was $3.49 \mathrm{X} 10^{6} / \mu \mathrm{L}$. His ESR was $25 \mathrm{~mm}$ in $1 \mathrm{st}$ hour, CRP was $2.81 \mathrm{mg} / \mathrm{dl}$, random blood
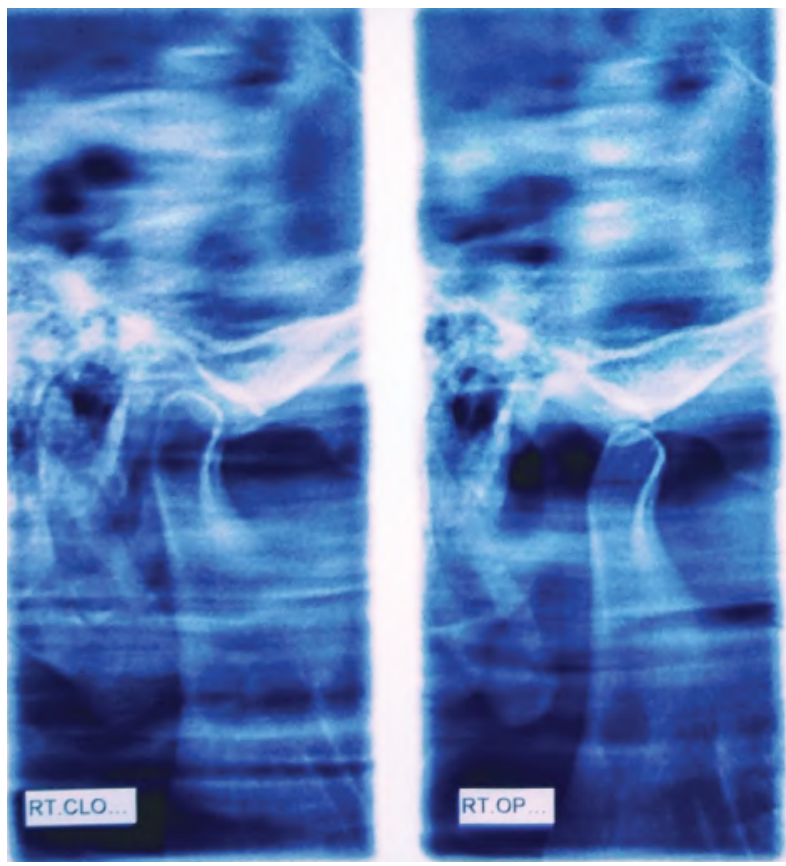

Figure-1a: Joint space narrowing and sclerosis in left TM joint
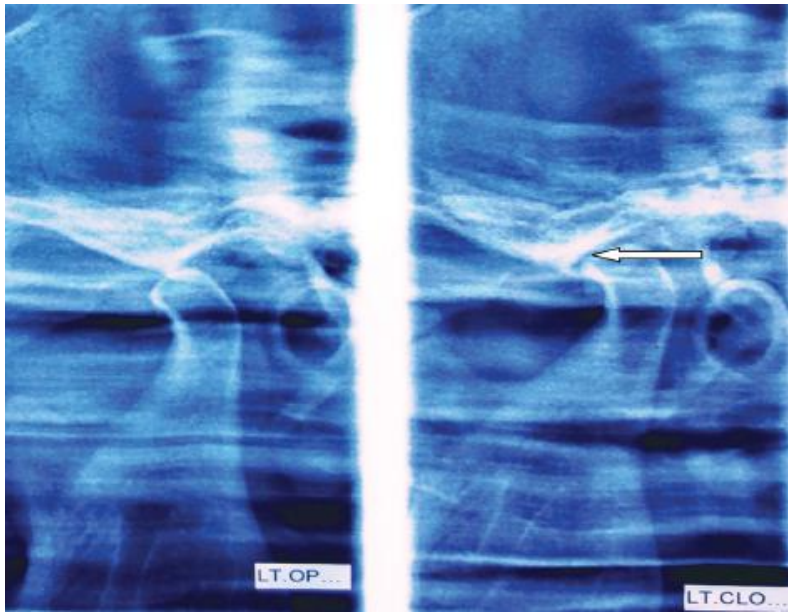

Figure-1b: Joint space narrowing and sclerosis in left TM joint sugar-7.2 mmol/L, HbAlc-6.1\%, SGPT was $16 \mathrm{U} / \mathrm{L}$, S. creatinine was $0.9 \mathrm{mg} / \mathrm{dl}$. Lipid profile was- total cholesterol- $232 \mathrm{mg} / \mathrm{dl}(<240 \mathrm{mg} / \mathrm{dl})$, HDL- $37 \mathrm{mg} / \mathrm{dl}$ $(>40 \mathrm{mg} / \mathrm{dl}) \mathrm{mg} / \mathrm{dl}$, LDL- $119.4 \mathrm{mg} / \mathrm{dl}(<130 \mathrm{mg} / \mathrm{dl})$ and TG was $325 \mathrm{mg} / \mathrm{dl}<200 \mathrm{mg} / \mathrm{dl}$ ). Urine RME showed normal, spot urinary micro albumin $31.71 \mathrm{mg} / \mathrm{dl}$ (<30mg/dl), ECG was normal, CXR P/A view was normal, RA test $54.9 \mathrm{IU} / \mathrm{ml}(<15 \mathrm{IU} / \mathrm{ml})$, AntI-CCP $365.2 \mathrm{U} / \mathrm{ml}$ $(25 \mathrm{U} / \mathrm{ml})$, Anti SSA $0.58 \mathrm{U} / \mathrm{ml}(<0.95 \mathrm{U} / \mathrm{ml})$, Anti-SSB $0.62 \mathrm{U} / \mathrm{ml}(<0.95 \mathrm{U} / \mathrm{ml}), \mathrm{X}$-ray left TM joint shows joint space narrowing and sclerosis. (Figure no. 1a, 1b), X-ray of hand showed normal findings (Figure no. 2).
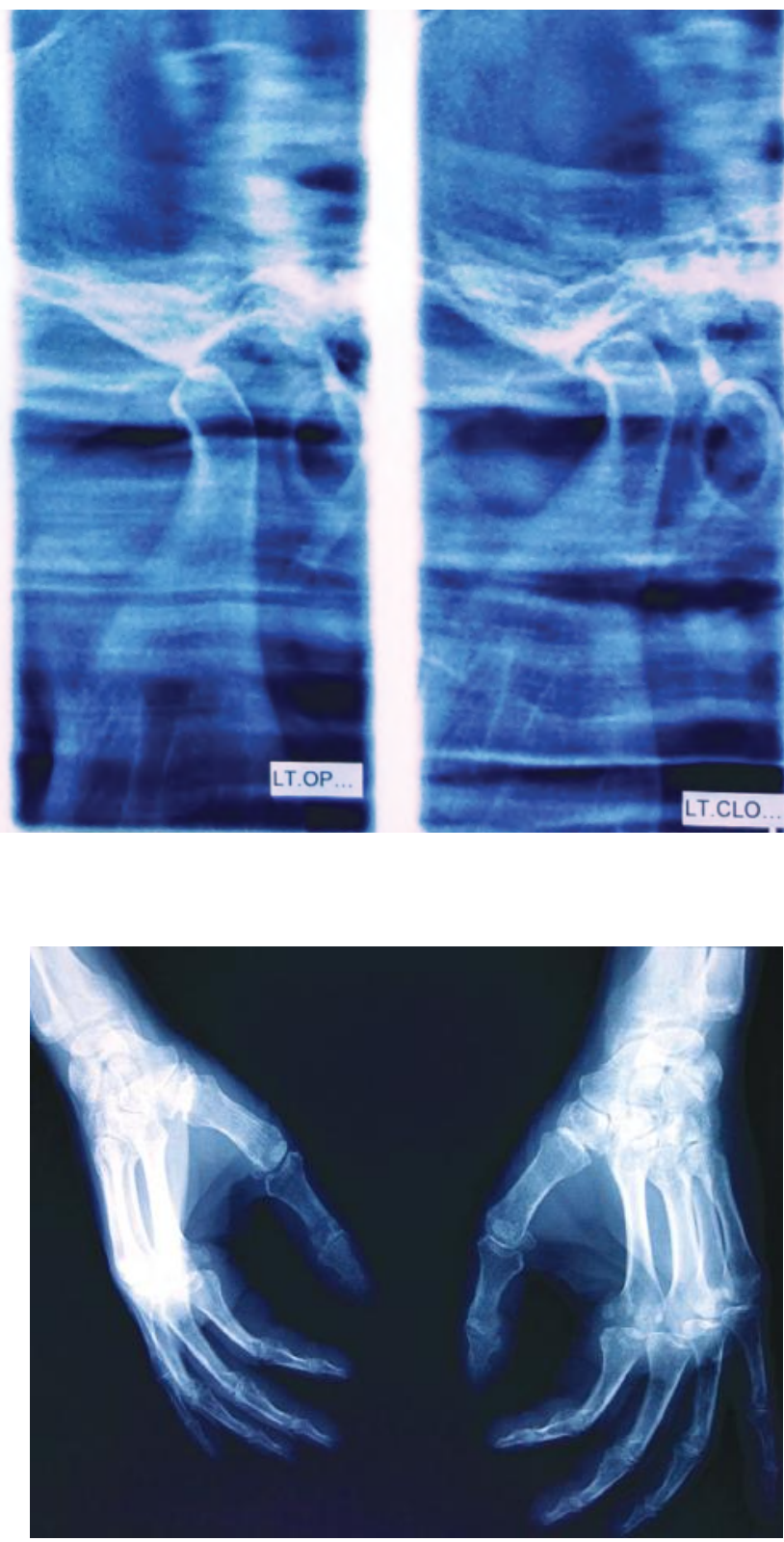

Figure-2: X-ray of both hands showing normal findings 


\section{DISCUSSION}

Rheumatoid arthritis is a systemic autoimmune condition with fluctuating manifestations. It is characterized by symmetric polyarticular inflammation, which can lead to progressive joint damage and is associated with substantial functional disability, morbidity, and accelerated mortality. The prevalence of RA is estimated at $1 \%$ in most developed countries, with a frequency ranging from less than or equal to $0.1 \%$ to $1.9 \%$ in surveys from different parts of the world ${ }^{6}$. The characteristic patient with RA often reports pain and swelling of the small joints of the hands, wrists, and feet, with prolonged morning stiffness, often lasting more than an hour. Early in the natural course, patients with RA may experience difficulty using their hands with routine activity, and pain in the forefeet with weight bearing or walking. Articular symptoms most often begin with stiffness, pain, and swelling involving the small joints of the hands and feet in a symmetric distribution, including the metacarpophalangeal (MCP), proximal interphalangeal (PIP), and metatarsophalangeal (MTP) joints. Patients commonly report a "gelling" phenomenon following periods of rest, which improves with activity. The joint examination often reveals swelling, tenderness, increased warmth, and limited range of motion. Other findings may include palmar erythema and subcutaneous nodules on extensor surfaces. Extra-articular features are more commonly seen in later disease. The condition characteristically spares the distal interphalangeal (DIP) joints impacting $<10 \%$ of cases $^{7}$ and also spares the thoracic and lumbosacral spine. With more advanced and longer duration of disease, RA may also involve atypical joints, including the temporomandibular joint.

The patient presented here was male and his age was 60 years and had only temporomandibular joint pain and stiffness without involvement of other joints and extra articular involvement of RA.

For diagnosis of RA, serological tests such as ESR, CRP, Rheumatoid Factor (RF), Anti CCP antibody was done. Our patient had raised ESR and CRP, high titer positive RF and Anti CCP antibody. X-ray left TMJ showed marginal sclerosis with joint space narrowing, right TMJ was normal. X-ray of both hands were normal.

Methotrexate remains the mainstay of treatment. Most of the patient responds well with this DMARD monotherapy. If does not respond or do not achieve treat to target to maximum tolerable dose of methotrexate then combination of other drugs like Sulfasalazine and/or Hydroxychloroquin of bDMARDs may be tried.
Our patient was treated with Methotrexate $10 \mathrm{mg} /$ week initially and later on dose was gradually increased to 20 $\mathrm{mg} /$ week with significant improvement on the basis of DAS28.

Isolated TMJ involvement as an initial presentation in RA is extremely rare, physician should be aware of this unusual presentation and RA should be considered as a differential diagnosis of TMJ arthritis even in the absence of other typical features of RA.

\section{CONCLUSIONS}

Isolated TMJ involvement as an initial presentation in RA is extremely rare. Physician should be aware of this unusual presentation and RA should be considered as a differential diagnosis of TMJ arthritis even in the absence of other typical features of RA.

\section{REFERENCES}

1. B. Bruce and G. Martin, "Temporomandibular disorders," in Burket's Textbook of Oral Medicine: Diagnosis and Treatment, pp. 271-306, Elsevier, Canada, 11th edition, 2008.

2. C. S. Crowson, E. L. Matteson, E. Myasoedova et al., "The lifetime risk of adult-onset rheumatoid arthritis and other inflammatory autoimmune rheumatic diseases," Arthritis \& Rheumatism, vol. 63, no. 3, pp. 633-639, 2011.

3. K. Moen, L. T. Bertelsen, S. Hellem, R. Jonsson, and J. G. Brun, "Salivary gland and temporomandibular joint involvement in rheumatoid arthritis: relation to disease activity," Oral Diseases, vol. 11, no. 1, pp. 27-34, 2005.

4. Delantoni A, Spyropoulou E, Chatzigiannis J, Papademitriou P. Sole radiographic expression of rheumatoid arthritis in the temporomandibular joints: A case report. Oral Surg Oral Med Oral Pathol Oral Radiol Endod. 2006; 102:e37-40.

5. Seymour RL, Crouse VL, Irby WB. Temporomandibular ankylosis secondary to rheumatoid arthritis. Report of a case. Oral Surg Oral Med Oral Pathol. 1975; 40:584-9.

6. Silman AJ: Rheumatoid arthritis, ed 4, St. Louis, 2001, Mosby Elsevier

7. Ichikawa N, Taniguchi A, Kobayashi $S$, et al: Performance of hands and feet radiographs in differentiation of psoriatic arthritis from rheumatoid arthritis. Int J Rheum Dis 15(5):462-467, 2012. 